\title{
HOMENS DE MANDO: AS REDES DE SOCIABILIDADES DOS CAPITÃES-MORES NA CAPITANIA DE PORTO SEGURO (1670-1682)
}

ANA PAULA SANTOS XAVIER*

UNIVERSIDADE ESTADUAL DE SANTA CRUZ ILHÉUS - BAHIA - BRASIL

O presente artigo tem por finalidade principal analisar a atuação dos capitães-mores nas questões militares na antiga capitania de Porto Seguro de 1670 a 1682, bem como o impacto das ações na vivência dos índios e colonos. Busca-se compreender, desse modo, como eram os recrutamentos desses oficiais, as possibilidades de mobilidade entre os agentes, assim como seus mecanismos de promoção. Assim, sendo possível reconstruir o perfil e a inserção sociopolítica e econômica destes oficiais, analisando as formas de reproduções sociais por meio das quais buscavam um melhor posicionamento no seio da sociedade colonial. As informações encontradas em diferentes grupos de documentos passaram pela metodologia do método indiciário

RESUMO para perceber os pequenos vestígios deixados por estes indivíduos e as ligações nominativas, para compreender as relações estabelecidas por eles a partir dos nomes que os cercam, ambos desenvolvidos pela Micro-História. Possibilitando, assim, conhecer algumas estratégias traçadas por estes indivíduos, influenciando para que eles fossem vistos e permanecessem como homens detentores de mando. Por fim, é necessário compreender uma localidade a partir das especificidades do seu tempo e com isso se as nomeações para os cargos dos capitães-mores atendiam a esses requisitos, tendo as relações baseadas em interesses maiores, exemplo disso é o caso de algumas ascensões ao posto do capitão-mor, baseadas em conflitos e intrigas.

Palavras-chave: Capitão-mor; Porto Seguro; Administração.

The present paper has the main purpose of analyzing the role of captains-mores in military matters in the old Captaincy of Porto Seguro from 1670 to 1682, as well as the impact of the actions on the experience of the Indians and colonists. Seeking to understand in this way how the recruitment of these officers was, the possibilities of mobility among agents, as well as their promotion mechanisms. Thus, it is possible to reconstruct the profile and the socio-political and economic insertion of these officers, analyzing the forms of social reproductions through which they sought a better position within colonial society. The information found in different groups of documents went through the methodology of the indictment method to understand the small traces left by these individuals and the nominative links, to understand the ABSTRACT relationships established by these subjects from the names that surround them, both developed by Micro-History. Thus, making it possible to know some of the strategies outlined by these individuals, influencing them to be seen and remain as men in charge. Finally, it is necessary to understand a locality from the specifics of its time and with that the appointments to the positions of captains-mores met these requirements, with relations based on greater interests, an example of this and the case of some ascension to the post of the captain. Captain-General, based on conflicts and intrigues.

Keywords: Chief Captain; Porto Seguro; Administration.

\footnotetext{
* Mestre em História pela Universidade Estadual de Santa Cruz (UESC). E-mail: annaxavier22@gmail.com.
} 


\section{INTRODUCÃO}

O presente artigo tem por finalidade analisar a atuação dos capitães-mores Pedro Serqueira da Veiga e Gaspar Borges de Novaes, na antiga capitania de Porto Seguro, entre os anos de 1670 a 1682 . O principal enfoque está na compreensão da função desses oficiais régiose do contexto em que foram nomeados , como também na percepção dos conflitos e das alianças tecidas para a permanência no cargo. Os capitães-mores eram oficiais militares responsáveis por administrar e defender o território português no Estado do Brasil. Como vassalos fiéis à Coroa e inseridos nas redes de poder e administração , usufruíram “ de prestígios, honras e privilégios e utilizavam suas carreiras como meio de ascensão social"1 .

Os serviços prestados à Coroa, mecanismo de ascensão social utilizado pelos colonos, possibilitou aos capitães o status necessário para mudar de vida em uma sociedade baseada em "ethos nobiliárquico". As mercês distribuídas modificaram consideravelmente a realidade da sociedade vigente da época, em uma localidade com um número significativo de negros e índios e ocasionalmente de mestiços.

A inserção desses sujeitos no jogo político proporcionou a esses detentores de poder certa estabilidade no governo português. As experiências e estratégias de vida desses agentes históricos foram importantes para fundamentar as barganhas e disputas que estavam inseridas no contexto da América Portuguesa.

Ao reconstruir a trajetória dessa elite militar, pensando que são premiados conforme o merecimento e a partir de mercês, as dinâmicas internas do Império Português serão analisadas partindo da ideia de uma monarquia pluricontinental que se definia por uma relação dialética que entrelaçam Coroa e Ultramar. Ambos dependiam "um do outro para ser e existir enquanto exercício de poder político e econômico, jurisdições e prerrogativas reiteradas e reforçadas justamente por meio dos vínculos que os articulavam entre si"2.

Dessa maneira, ao mesmo tempo em que se reconheceu a importância dos poderes locais para a efetivação do poder régio em muitos de seus domínios, descobriu que a vitalidade dele era indissociável da formação de elites locais, ou seja, essas conseguiram acumular poderes capazes de fazer resistência à Coroa.

\footnotetext{
${ }^{1}$ RICUPERO, R. A formacão da elite colonial no Brasil. 1530-1630. São Paulo: Alameda, 2009.

2 FRAGOSO, J.; GOUVÊA, M. F. Na trama das redes: política e negócios no império português, séculos XVI-XVIII. - Rio de Janeiro: Civilização Brasileira, 2010.
} 
A partir dessa discussão, busca-se analisar as fontes a fim de compreender complexidade das experiências históricas $\quad$ O $\quad \mathrm{s}$ sujeitos são analisados nas suas interconexões com outros indivíduos e com as estruturas de poder, entendendo-os como agentes históricos condicionados às normas e às práticas $\mathrm{d}$ e seu tempo. Nesse sentido, o método indiciário teorizado por Ginzburg ${ }^{3}$ e o fio condutor da metodologia de ligações nominativas de Ginzburg ${ }^{4}$ são utilizados para auxiliar na análise da trajetória desse $\mathrm{s}$ indivíduos . É necessário considerar as estratégias e os recursos que tais oficiais utilizaram e adquiriram para consolidar as suas posições de mando , bem como a importância dessas ações nas barganhas e disputas em que os mesmos estavam inseridos, dentro da América portuguesa.

\section{“A SERVICO DE EL' REI MEU SENHOR”: O CASO DO CAPITÃO-MOR PEDRO SERQUEIRA DA VEIGA}

O capitão-mor Pedro Serqueira da Veiga foi um vassalo fiel à Coroa e um militar de carreira. Entre os anos de 1645 e 1648, envolveu-se em uma grande contenda com o capitãomor Paulo Barbosa, que na época ocupava o cargo de capitão-mor, ouvidor e administrador do pau-brasil na capitania de Porto Seguro.

Os ocupantes de cargos militares tinham uma relação baseada em conflitos e alianças, tanto com os colonos como com os seus superiores, fosse algum militar com patente mais alta, fossem os enviados diretos da Coroa. Essas relações eram baseadas em interesses individuais ou coletivos.

Manter a harmonia durante a vigência do cargo tinha muita importância para o futuro do posto de capitão-mor ou qualquer outro. Um bom serviço prestado à Coroa levaria aquele indivíduo a permanecer por mais tempo no cargo, como também ser nomeado para postos mais altos.

A vida militar de Pedro Serqueira da Veiga começou antes de 1645. A primeira nomeação para o cargo de capitão-mor foi por motivos do falecimento do antecessor, em 1655. Segundo a fonte:

\footnotetext{
${ }^{3}$ GINZBURG, C. "Sinais: raízes de um paradigma indiciário". In. Mitos, emblemas, sinais: morfologia e história. São Paulo: Companhia das Letras, 1989, p. 149

${ }^{4}$ GINZBURG, C. "O nome e o como" In: A micro-história e outros ensaios. Rio de Janeiro: DIFEL, 1991, p. 177-178.
} 
[...] por conta do falecimento de Francisco de Amorim ficou vago o cargo de capitão-mor da Capitania de Porto Seguro, e convém provê-lo em pessoa de valor, prática da disciplina militar, e experiência de guerra; tendo eu consideração ao bem que todas estas qualidades concorrem na de Pedro Serqueira da Veiga, e á satisfação, zelo, e pontualidade, com que me consta haver servido a Sua Majestade em diferentes ocasiões, e por várias vezes o mesmo cargo. ${ }^{5}$

Os inúmeros elogios impostos a Pedro Serqueira da Veiga demonstram como suas relações de amizade e poder eram profundas. Dentro de uma dinâmica hierárquica de administração política e militar da época, pode-se dizer que ele consolidou sua influência no poder local passando no período de dez anos de provedor-mor a três posses do cargo de capitãomor, como mostra o quadro 1.

Esse fato demonstra a grande rotatividade existente nos cargos na capitania de Porto Seguro. No entanto, também poderia haver permanência de determinadas pessoas em outros cargos; aquele indivíduo que outrora fora provedor, três anos depois poderia ser provido no cargo de capitão-mor. Diante dessa lógica, pesavam também "impedimentos como ausências e falta de resultados de residências em curso ou com abusivas exigências de mercês que obrigavam a renhidas negociações "[...] Por isso repetiam-se os nomes em carteiras para um posto e depois outro"'.

No quadro seguinte pode-se observar a repetição dos nomes nos cargos de capitão-mor. Pedro Serqueira da Veiga esteve no cargo por três diferentes momentos, em uma das vezes assumindo o posto no lugar do seu cunhado, Francisco Amorim. Dois anos depois, em 1657, recebe novamente a carta patente de capitão-mor, ficando no cargo até 1659.

${ }^{5}$ DOCUMENTOS HISTÓRICO DA BIBLIOTECA NACIONAL. Patente do cargo de capitão-mor, que vagou por falecimento de Francisco Amorim, da Capitania de Porto Seguro, provida na pessoa de Pedro Serqueira da Veiga. Bahia, 23 de junho de 1655 - DHBN - v. 031. ${ }^{6}$ CUNHA, M. S. da. Redes sociais e decisão política no recrutamento dos governantes das conquistas, 1580 - 1640 In: FRAGOSO, João; GOUVÊA, Maria de Fatima (Org.). Na trama das redes: Política e negócio no Império Português, séculos XVI - XVIII. Rio de Janeiro: Civilização Brasileira, 2010, p. 137. 


\section{Quadro 1. Tempo de serviço dos capitães-mores no exercício de seu cargo na Capitania de Porto Seguro, 1651-1670}

\begin{tabular}{lc}
\hline Capitão-mor & Duração no cargo \\
\hline Paulo Barbosa & $1644-1647$ \\
Francisco Amorim & $1647-1651$ \\
Francisco Amorim & $1651-1655$ \\
Pedro Serqueira da Veiga & $1655-1657$ \\
Pedro Serqueira da Veiga & $1657-1659$ \\
Rafael Barbosa & $1659-1660$ \\
Diogo Ribeiro de Sande & $1660-1663$ \\
Pedro Serqueira da Veiga & $1663-1667$
\end{tabular}

Fonte: ARQUIVO HISTÓRICO ULTRAMARINO. Consulta do Conselho Ultramarino sobre o capitão Paulo Barbosa, que, nomeado capitãomor, ouvidor e administrador do pau-brasil da capitania de Porto Seguro, arribara a Setubal por causa do mau tempo e foi por isso destituído e dado lugar a Nicolau de Brito; pede para ser restituído ou melhorado em outro posto, para não pereça sua honra e crédito. Lis boa, 31 de outubro de 1644. AHU_ACL_CU_005, Cx. 09, Doc. 1082. DOCUMENTOS HISTÓRICOS DA BIBLIOTECA NACIONAL. Carta patente do cargo de capitão - mor da capitania de Porto Seguro na pessoa do capitão Francisco Amorim. Bahia, 24 de janeiro de 1651 - DHBN - v. 031. DOCUMENTOS HISTÓRICOS DA BIBLIOTECA NACIONAL. Patente do cargo de capitão-mor, que vagou por falecimento de Francisco Amorim, da Capitania de Porto Seguro, provida na pessoa de Pedro Serqueira da Veiga. Bahia, 23 de junho de 1655 - DHBN - v. 031. DOCUMENTOS HISTÓRICOS DA BIBLIOTECA NACIONAL. Patente ao posto de capitão-mor da capitania de Porto Seguro provida na pessoa de Pedro Serqueira da Veiga. Bahia 08 de novembro de 1657 - DHBN - v. 31. DOCUMENTOS HISTÓRICOS DA BIBLIOTECA NACIONAL. Patente de capitão - mor da capitania de Porto Seguro provida na pessoa de Rafael Barbosa. Bahia, 17 de setembro de 1659 DHBN - V. 031. DOCUMENTOS HISTÓRICOS DA BIBLIOTECA NACIONAL. Patente de capitão - mor de Porto Seguro provido na pessoa de Diogo Ribeiro de Sande. Bahia, 12 de julho de 1660 - DHBN - v. 031. DOCUMENTOS HISTÓRICOS DA BIBLIOTECA NACIONAL. Patente do posto de capitão - mor da capitania de Porto Seguro de que foi provida a pessoa de Pedro Serqueira da Veiga. Bahia 04 de julho de 1663 - DHBN -v.031.

A documentação analisada sobre Pedro Serqueira encontrada no Arquivo Histórico Ultramarino e nos Documentos Históricos da Biblioteca Nacional não foi exaustiva, mas permitiu observar que sua trajetória é similar a de outros capitães-mores. Outro aspecto que a documentação demonstrou é a grande rotatividade que havia no cargo de capitão-mor da capitania de Porto Seguro. Além disso, mostra a rede de sociabilidade formada por esses agentes da Coroa para que seus privilégios conquistados fossem mantidos.

As ações e performances de Pedro Serqueira foram seguidas, através das fontes, tendo como fio condutor a metodologia de ligações nominativas, que segundo Ginzburg ${ }^{7}$ é uma forma de possibilitar um acompanhamento do destino de um indivíduo, observando a complexa rede

${ }^{7}$ GINZBURG, 1991, p. 177-178. 
de relações e os contextos nos quais os atores constroem sua história. É dessa forma que parte das experiências e estratégias de vida desses agentes históricos podem ser compreendidas.

Como analisado anteriormente, a permanência de um único nome em um mesmo cargo ou em cargos relacionados ao governo da capitania explica-se pelas redes de amizade e poder que esses indivíduos conseguiam articular e manter em torno de si. Ter os homens da fazenda, da justiça e da defesa unidos dentro de uma ótica de troca de interesses possibilitava que esses indivíduos conseguissem controlar as decisões que dependiam apenas da capitania.

Todos os militares citados possuíam algum tipo de relação, seja de parentesco ou de amizade, interferindo diretamente para que conseguissem o cargo. Pedro Serqueira da Veiga, conseguiu o cargo por conta do falecimento do seu cunhado, o capitão-mor Francisco Amorim. A carta-patente foi concedida pelo conde de Atouguia, governador-geral, justificando que Pedro Serqueira possuía: "prática na disciplina e experiência de guerra". Nas duas vezes em que assumiu o cargo ficou claro na sua carta-patente o fato de ter "a satisfação, zelo e pontualidade com que me consta haver servido a Sua Majestade em diferentes ocasiões, e por várias vezes o mesmo cargo" 8 .

Ao contrário de outras partes da carta-patente, esse ponto possibilita identificar que de fato Pedro Serqueira da Veiga possuía alguma experiência em cargos militares, já que "apesar de todas as diferenças existentes entre as diversas áreas do Império português, presente nas "quatros partes do mundo", as práticas e instituições presentes eram semelhantes: "conquistas", "mercês", "câmaras municipais"”. Assim, as relações de amizades que tinha poderiam até ser responsáveis para que conseguisse o cargo, porém a sua experiência militar contribuía para que permanecesse nele.

As mudanças implementadas pela restauração bragantina tiveram grandes responsabilidades nas mudanças ocorridas nas possessões além-mar. Para os vassalos, era necessário habituar-se com a nova política vigente dos Bragança. Para a Coroa portuguesa beneficiar os súditos com mercês era uma forma de mantê-los de alguma forma leais ao novo governo. Essa rede de sociabilidade entre os habitantes da capitania de Porto Seguro era

\footnotetext{
${ }^{8}$ DOCUMENTOS HISTÓRICOS DA BIBLIOTECA NACIONAL. Patente ao posto de capitão-mor da capitania de Porto Seguro provida na pessoa de Pedro Serqueira da Veiga. Bahia 08 de novembro de 1657 - v. 31.

9 ALMEIDA, W. S. de. Gente da terra: relações de poder na capitania do Espírito Santo (séculos XVI E XVII). Espírito Santo, 2019. Dissertação (Mestrado em História) - UFES, Vitória, 2019, p. 46.
} 
baseada numa ótica de conflitos e alianças constantes; os acordos eram moldados a partir dos interesses que estavam em jogo.

O trânsito pelo espaço ultramarino desses funcionários régios não era apenas no Estado do Brasil; em muitos momentos as experiências eram adquiridas nos territórios além-mar da Coroa. As experiências que os vassalos acumulavam em todas as possessões além-mar, como por exemplo em Angola, nas guerras naquele território, não eram desprezadas quando atravessavam o Atlântico.

Dentro desse contexto, temos as atuações dos capitães-mores na capitania de Porto Seguro, que tinham como ponto principal a repressão contra os povos indígenas que viviam na região. As experiências acumuladas permitiram a esses homens um combate intenso contra toda e qualquer força contrária às políticas de controle da Coroa.

Os homens analisados tinham uma larga rede de amizades que possibilitou que suas administrações obtivessem algum êxito quando passaram pelo governo da capitania. A ligação com outras pessoas com algum prestígio garantia certa estabilidade; sem elas as vivências administrativas seriam instáveis, ocasionando para esses homens penas duras, afetando diretamente suas carreiras militares.

Por fim, a inserção desses sujeitos no jogo político português proporcionou a esses detentores de poder certa estabilidade no governo. A permanência dos nomes no mesmo cargo ou em cargo relacionados demonstra a grande rotatividade nos cargos da capitania de Porto Seguro, formando uma teia de poder que apenas se dissolvia quando um deles era o autor de algum crime não perdoado pela Coroa.

\section{"HONRAS. PRIVILÉGIOS E LIBERDADES": O CAPITÃO-MOR GASPAR BORGES NOVAES}

Em 25 de junho de 1682, Gaspar Borges Novaes foi nomeado pela primeira vez para o cargo de capitão-mor da capitania de Porto Seguro. 
Hei por bem de o eleger e nomear (como em virtude da presente elejo e nomeio) capitão-mor da dita capitania enquanto Sua Alteza o houver assim por bem e não mandar outra coisa para que o seja, use e exerça com todas as honras [...]. ${ }^{10}$

A trajetória do capitão-mor Gaspar Borges de Novaes na capitania de Porto Seguro começou em 1661 como capitão de Infantaria. Mais de vinte anos depois, Gaspar Borges de Novaes aparece recebendo a sua provisão para o cargo de capitão-mor da capitania de Porto Seguro, sem muito alarde ou com qualquer indicativo de quais serviços prestados anteriormente que justificassem a sua primeira nomeação pela Coroa. Helmo Ballarini aponta que:

[...] existia desde o século XVI e principalmente ao longo do século XVII o desenvolvimento de uma noção de mercê remuneratória que se consolidava em Portugal e era tão grande a importância política da economia das mercês, que ao longo do Antigo Regime inúmeros esforços foram feitos para organizá-la. ${ }^{11}$

Na primeira vez que assumiu o cargo, Gaspar Borges de Novaes ocupou o lugar de João Viegas Xorte, recebendo das mãos do antigo capitão-mor um legado pessoal, já que João Viegas Xorte saiu do comando da capitania em alta conta com a Coroa e com os moradores da capitania, por seus serviços prestados, principalmente no sufocamento de revoltas indígenas que aconteceram em Porto Seguro.

Nessa primeira empreitada como capitão-mor Gaspar Borges, com apenas dois anos no cargo, recebeu uma confirmação e autorização para continuar no cargo. Em 04 de setembro de 1684 ele recebeu uma nova nomeação, como se vê nos documentos compulsados.

Pela informação que tive de Gaspar Borges Novaes haver procedido no governo dessa capitania com satisfação, o provi de capitão-mor della, enquanto El-rei meu senhor o houver assim por bem, ou não mandar outra causa, vossas mercês o tenham assim entendido, e lhe mandem registrar a sua patente, para que vá

${ }^{10}$ DOCUMENTOS HISTÓRICOS DA BIBLIOTECA NACIONAL. Registro da carta patente de capitão-mor da capitania de Porto Seguro que se proveu na pessoa de Gaspar Borge Novaes. Bahia, 25 de junho de 1682 - v.028

${ }^{11}$ BALLARINI, H. M. A Ordem de Cristo no contexto de uma economia de mercês. Critérios de provimento de cargos e ofícios nos séculos XVII e XVIII: o caso da capitania do Espírito Santo / Helmo Magno Ballarini. - 2016, p.85. 
continuando com o dito posto na forma dela, que espero de sua prudência e bom modo que tenham esses moradores muito que estimar as suas ações [...]. ${ }^{12}$

Com essa carta-patente expedida com apenas dois anos de serviços, verifica-se uma intenção prévia da Coroa de que Gaspar Borges Novaes permanecesse no cargo de capitão-mor da capitania de Porto Seguro, o que de fato ocorreu por mais de três anos, já que até este momento não há nenhum registro de nova carta-patente e confirmação de cargo com esse tempo de atuação para um outro capitão-mor em Porto Seguro.

A segunda vez que Gaspar Borges Novaes assumiu o cargo de capitão-mor foi em 1688,

[...] haver provido na pessoa de Gaspar Borges de Novaes no posto de capitãomor do Porto Seguro que estava exercitando [...] Patente de confirmação por que Vossa Magestade faz mercê a Gaspar Borges de Novaes de o confirmar no posto de capitão-mor da capitania do Porto Seguro em que o proveu o governador [... ${ }^{13}$

A situação da sua segunda nomeação, ou terceira, se levar em consideração a confirmação que ocorreu em 1684, foi totalmente diferente da primeira. Depois de cinco anos ocupando a posição de capitão-mor da capitania de Porto Seguro, Gaspar Borges de Novaes saiu do cargo. No lugar dele assumiu Domingo Ferrás de Araújo,

[...] a satisfação com que tem servido a El-rei meu senhor seis annos e cinco dias de soldado e alferes da Companhia do capitão Bartholomeu Nabo Corrêa do terço do mestre de Campo Alvaro de Azevedo havendo procedido no decurso deste tempo muito como devia às suas obrigações e ao honrado conceito que tenho de seu procedimento esperando delle que nas do dito posto se haverá muito conforme a confiança que faço de seu procedimento e qualidades. ${ }^{14}$

\footnotetext{
${ }^{12}$ DOCUMENTOS HISTÓRICOS DA BIBLIOTECA NACIONAL. Carta para os officiaes da camara de Porto Seguro. Bahia, 04 de setembro de 1684 - V. 09

13 DOCUMENTOS HISTÓRICOS DA BIBLIOTECA NACIONAL. Registro da carta patente de Sua Magestade por que confirmou no posto de capitão-mor da capitania do Porto Seguro a Gadpar Borges de Novaes. Bahia, 03 de julho de 1688 - V.029

${ }^{14}$ DOCUMENTOS HISTÓRICOS DA BIBLIOTECA NACIONAL. Registro da patente por que foi provido Domingos Ferrás de Araújo no posto de capitão-mor da capitania do Porto Seguro por tempo de um anno. Bahia, 13 de maio de 1687 - V.029.
} 
A nomeação de Domingos Ferrás de Araújo foi estabelecida apenas em um ano, partindo do princípio de que Gaspar Borges de Novaes retornou depois desse intervalo de tempo e o fato de que a sua primeira carta-patente não possuía nenhum relato de serviços prestados à Coroa, diferente da segunda, em que já era possível identificar seus feitos e serviços prestados. Esse tempo de afastamento foi utilizado por Gaspar Borges de Novaes para prestar serviços à Coroa, que a posteriori seriam utilizados para o nomear, novamente, como capitão-mor de Porto Seguro, como aponta a documentação:

[...] pela satisfação com que tem servido nas occasiões que se offereceram principalmente na em que mandou setenta e tantos homens ao rio Patipe e inimigo que naquelle lugar veio a fazer aguada e lenha correndo todo o gasto por sua conta e mandando mais gente a cabichabiba matarem quatro hollandezes além de alguns feridos assistindo pessoalmente com um filho e seu escravo aos caminhos que se fizeram para defesa da dita villa mandando fazer carretos para duas peças que estavam desmontadas $[\ldots] .^{15}$

Como aponta o trecho acima, a presença de pessoas pertencentes a outros territórios era constante nas redondezas da capitania de Porto Seguro, o que era proibido pela Coroa. Pela ação coordenada por Gaspar Borges de Novaes esses indivíduos que aparentemente não tinham a intenção de uma permanência harmoniosa na região foram rechaçados. A presença de holandeses, destacada no trecho, aponta para a presença de conflitos não apenas com os grupos indígenas presentes na localidade, mas com outros europeus.

Essa habilidade de Gaspar de Borges Novaes e o conhecimento dos interiores da capitania de Porto Seguro se explicam por ele, provavelmente, ser morador da capitania e conhecer muito bem todo o território. Rodrigo Ricupero aponta que:

[...] o funcionário colonial, com poucas exceções, não representava uma camada autônoma na colônia, antes confundia-se com os grupos poderosos locais, sendo muitas vezes, ao mesmo tempo, funcionário régio, senhor de engenho ou

${ }^{15}$ DOCUMENTOS HISTÓRICOS DA BIBLIOTECA NACIONAL. Registro da carta patente de Sua Magestade por que confirmou no posto de capitão-mor da capitania do Porto Seguro a Gaspar Borges de Novaes. Bahia, 03 de julho de 1688 -DHBN - v.029 
proprietário de terras, soldado e ainda, eventualmente, também envolvendo-se em atividades em mercantis. ${ }^{16}$

Possivelmente por ser proprietário de terras na capitania de Porto Seguro, o capitão-mor Gaspar Borges Novaes tinha uma melhor mobilidade pelo território da capitania. Esse conhecimento prévio do local de atuação lhe facilitava toda e qualquer ação. Baseando-se nos estudos de Rodrigo Ricupero, pode-se supor ser também a situação do capitão-mor Gaspar Borges de Novaes, que com a união de experiência, conhecimento territorial e o fato de ser proprietário de terra tornou-se o candidato ideal para administrar a capitania de Porto Seguro.

Algo a questionar é o fato de Gaspar Borges de Novaes não receber nenhum soldo como capitão-mor e mesmo assim financiar as entradas nas matas de Porto Seguro, levando consigo seu filho e um escravo "[...] no dito posto de capitão-mor de Porto Seguro em que está provido pelo governador e capitão geral do Estado do Brasil com o qual posto não haverá soldo algum da minha fazenda $[\ldots]^{p 17}$.

Esses dois fatos, financiamento de entradas nas matas e a posse de um escravo, com o adendo de não receber nenhum soldo fixo por parte da Coroa, possivelmente, reafirmam a hipótese de que Gaspar Borges de Novaes era morador da capitania de Porto Seguro, pertencia à elite da capitania e era proprietário de terras, conforme aponta Maria Fernanda Bicalho: "que as elites locais no Brasil eram formadas por grupos e indivíduos que, em razão do exercício de funções administrativas e do recebimento de mercês régias, acumularam uma grande riqueza" 18 .

Com isso a mobilidade daqueles que ocupavam os cargos de capitães-mores na capitania de Porto Seguro era importante para adquirir experiência e com isso a nomeação aos cargos, ascender socialmente e alcançar status na localidade. A questão da mobilidade foi para Leonardo Paiva de Oliveira uma:

[...] estratégia adotada pela Coroa visava ampliar a capacidade de percepção de seus governantes para a diversidade dos problemas enfrentados, levando-os a

\footnotetext{
${ }^{16}$ RICUPERO, 2009, p.152.

${ }^{17}$ DOCUMENTOS HISTÓRICOS DA BIBLIOTECA NACIONAL. Registro da carta patente de Sua Magestade por que confirmou no posto de capitão-mor da capitania do Porto Seguro a Gadpar Borges de Novaes. Bahia, 03 de junho de 1688 - V.029

${ }^{18}$ BICALHO, M. F. B. Elites coloniais: a nobreza da terra e o governo das conquistas. História e historiografia. In: MONTEIRO, Nuno G.; CARDIM, Pedro; CUNHA, Mafalda S. da (Org.). Optima Pars: elites ibero-americanas do Antigo Regime. Lisboa: Imprensa de Ciências Sociais, 2005. p. 73.
} 


\begin{abstract}
experimentar os ambientes mais distintos, tendo em consideração a pluralidade geográfica e cultural de suas conquistas, assim como também as semelhanças entre eles, para que a partir deste ganho de experiência e alargamento de visão, os sujeitos envolvidos nessa circulação pudessem fazer uma melhor administração. ${ }^{19}$
\end{abstract}

Entretanto, aqueles que não percorreram as possessões além-mar em busca de cargos da Coroa e permaneceram nas capitanias também tinham importância e conseguiram ascender socialmente acumulando riquezas, status e privilégios, atrelados a cargos na capitania de Porto Seguro.

Ressalta-se que a capitania de Porto Seguro estava interligada com as outras possessões além-mar, sendo palco de atuação de homens bons da Coroa que tinham larga experiência militar e que dessa forma conseguiram acessar altos escalões da sociedade portuguesa da América.

A documentação sobre Gaspar Borges Novaes, encontrada nos Documentos Históricos da Biblioteca Nacional, permitiu observar que sua trajetória é diferente da de outros capitãesmores porque Gaspar Borges de Novaes não tinham nenhuma experiência militar, quando exerceu o cargo de capitão-mor, necessitando fazer entrada nas matas da capitania de Porto Seguro, para justificar seu pedido de carta patente.

Nesse sentido, o método indiciário teorizado por Ginzburg ${ }^{20}$, que consiste na disposição de realizar operações capazes de analisar e reconstruir fatos históricos a partir dos vestígios deixados pelas fontes fornece subsídios para qualificar a análise documental. Para isso, se faz primordial atentar para o momento histórico em que os documentos relativos ao episódio são produzidos, os sujeitos que produziram e a dinâmica política do período. Reforçando a necessidade da utilização do método indiciário para a reconstrução das performances administrativas de pessoas como Gaspar Borges de Novaes.

\footnotetext{
${ }^{19}$ OLIVEIRA, L. P. de. Capitães-mores das capitanias do norte: perfis, trajetórias e hierarquias espaciais no Rio Grande e Ceará (1656 1755). Dissertação (Mestrado em História), UFRN, Natal, 20018. p. 17.

${ }^{20}$ GINZBURG, 1989 , p. 149
} 


\section{CONSIDERACÕES FINAIS}

No século XVII, Portugal ainda travava guerras tanto no Reino como nas possessões ultramarinas, com adversários europeus e com os grupos originários do Brasil.

Os militares designados para os postos de governo locais tinham como função principal defender as capitanias de qualquer ataque. Nas capitanias do Brasil, a experiência em lutas no reino e no combate aos índios contava em grande grau para obtenção de mercês da Coroa, em retribuição a esses serviços. Em sua maioria, eram essas experiências que pesavam no perfil dos homens que postulavam ao cargo de capitães-mores na antiga capitania de Porto Seguro.

Dessa maneira, esse artigo buscou analisar a atuação de dois capitães-mores na capitania de Porto Seguro, que tinham como regra principal a repressão contra os povos indígenas que viviam ou transitavam pela região. Era essa experiência, no entender da Coroa, que permitiria a esses homens um combate intenso a toda e qualquer força contrária às suas políticas para o território. Com esses atores essenciais para a manutenção do Império, a Coroa beneficiava aqueles que melhor se destacavam no seu serviço.

Os capitães-mores analisados Pedro Serqueira da Veiga e Gaspar Borges de Novaes têm em comum o fato de serem moradores da capitania de Porto Seguro e conhecerem muito bem o território da capitania. Uma das diferenças entre os dois é que Pedro Serqueira era um homem que tinha certa experiência militar, enquanto Gaspar Borges adentrou pelo território da capitania, enfrentando e apresando índios, e em combate direto a invasores externos.

Algo a pontuar, é que mesmo com essas diferenças e semelhanças, os homens analisados tinham uma larga rede de amizade, que lhes possibilitou uma administração exitosa na capitania. A ligação com outras pessoas com algum prestígio garantiu uma certa estabilidade. Sem essas ligações, familiares e de amizade, as vivências administrativas seriam conflituosas, ocasionando a estes homens danos pessoais futuros, capazes de afetar diretamente suas carreiras.

Na composição da elite porto-segurense as relações de sociabilidade tinham que ser bem demarcadas, a fim de que se pudesse articular poder suficiente para negociar privilégios. Tais redes de amizades eram importantes para que esses privilégios permanecessem sob seu controle, contribuindo para manter seus ganhos, seu poder e sua proteção junto à Coroa. 
É neste contexto que se entende que algumas de suas ações tiveram como objetivo modificar a dinâmica colonial estabelecida. Um exemplo disso foi a atuação dos capitães-mores na criação de aldeamentos, em recompensa às suas iniciativas de promover entradas ao interior do território em busca da mão de obra indígena para escravização.

Por fim, articulando com as elites as responsabilidades e os benefícios inerentes ao cargo que ocupavam, os capitães-mores procuraram manter o controle dos elementos mais importantes no jogo de forças locais. Tais movimentos devem, contudo, ser compreendidos em conjunto dentro da dinâmica colonial portuguesa.

\section{REFERÊNCIAS}

\section{Fontes}

BIBLIOTECA NACIONA. Documentos Históricos. Carta para os officiaes da camara de Porto Seguro. Bahia, 04 de setembro de 1684 - v. 09. 09.

Carta para os officiaes da camara de Porto Seguro. Bahia, 04 de setembro de 1684 - v.

Patente do cargo de capitão-mor, que vagou por falecimento de Francisco Amorim, da Capitania de Porto Seguro, provida na pessoa de Pedro Serqueira da Veiga. Bahia, 23 de junho de 1655 - v. 031.

Patente ao posto de capitão-mor da capitania de Porto Seguro provida na pessoa de Pedro Serqueira da Veiga. Bahia 08 de novembro de 1657 - v. 31.

Registro da patente por que foi provido Domingos Ferrás de Araújo no posto de capitãomor da capitania do Porto Seguro por tempo de um anno. Bahia, 13 de maio de 1687 - v.029.

. Registro da carta patente de Sua Magestade por que confirmou no posto de capitão-mor da capitania do Porto Seguro a Gaspar Borges de Novaes. Bahia, 03 de julho de 1688 - v.029.

. Registro da carta patente de Sua Magestade por que confirmou no posto de capitão-mor da capitania do Porto Seguro a Gaspar Borges de Novaes. Bahia, 03 de julho de 1688 - v.029 09.

. Carta para os officiaes da camara de Porto Seguro. Bahia, 04 de setembro de 1684 - v.

Registro da carta patente de Sua Magestade por que confirmou no posto de capitão-mor da capitania do Porto Seguro a Gaspar Borges de Novaes. Bahia, 03 de julho de 1688 - v.029 
. Registro da patente por que foi provido Domingos Ferrás de Araújo no posto de capitãomor da capitania do Porto Seguro por tempo de um anno. Bahia, 13 de maio de 1687 - v.029.

Registro da carta patente de Sua Magestade por que confirmou no posto de capitão-mor da capitania do Porto Seguro a Gaspar Borges de Novaes. Bahia, 03 de julho de 1688 - v.029

Registro da carta patente de capitão-mor da capitania de Porto Seguro que se proveu na pessoa de Gaspar Borge Novaes. Bahia, 25 de junho de 1682 - v.028

Registro da carta patente de capitão-mor da capitania de Porto Seguro que se proveu na pessoa de Gaspar Borge Novaes. Bahia, 25 de junho de 1682 - v.028

Registro da carta patente de Sua Magestade por que confirmou no posto de capitão-mor da capitania do Porto Seguro a Gaspar Borges de Novaes. Bahia, 03 de junho de 1688 - v.029

\section{Obras Gerais}

ALMEIDA, W. S. de. Gente da terra: relações de poder na capitania do Espírito Santo (séculos XVI E XVII). Espírito Santo, 2019. Dissertação (Mestrado em História), UFES, Vitória, 2019.

BALLARINI, H. M. A Ordem de Cristo no contexto de uma economia de mercês. Critérios de provimento de cargos e ofícios nos séculos XVII e XVIII: o caso da capitania do Espírito Santo / Helmo Magno Ballarini. - 2016.

BICALHO, M. F. B. Elites coloniais: a nobreza da terra e o governo das conquistas. História e historiografia. In: MONTEIRO, Nuno G.; CARDIM, Pedro; CUNHA, Mafalda S. da (Org.). Optima Pars: elites ibero-americanas do Antigo Regime. Lisboa: Imprensa de Ciências Sociais, 2005.

CUNHA, M. S. da. Redes sociais e decisão política no recrutamento dos governantes das conquistas, 1580 - 1640. In: FRAGOSO, João; GOUVÊA, Maria de Fatima (Org.). Na trama das redes: Política e negócio no Império Português, séculos XVI - XVIII. Rio de Janeiro: Civilização Brasileira, 2010.

GINZBURG, Carlo. Mitos, emblemas, sinais: morfologia e história. São Paulo: Companhia das Letras, 1989.

GINZBURG, Carlo. A micro-história e outros ensaios. Rio de Janeiro: DIFEL, 1991. p. 177178.

FRAGOSO, J.; GOUVÊA, M. F. Na trama das redes: política e negócios no império português, séculos XVI-XVIII. Rio de Janeiro: Civilização Brasileira, 2010. 
OLIVEIRA, L. P. de. Capitães-mores das capitanias do norte: perfis, trajetórias e hierarquias espaciais no Rio Grande e Ceará (1656 - 1755). Dissertação (Mestrado em História), UFRN, Natal, 20018.

PÉREZ, J. M. S. A estratégia dos Habsburgo para a América Portuguesa. In: ALMEIDA, S. C. C. de.; SILVA, G. C. de M.; Silva, K. V.; Souza, G. F. C. de (Org.). Políticas e estratégias administrativas no mundo Atlântico. Recife: Ed. Universitária da UFPE, 2012.

RICUPERO, R. A formação da elite colonial no Brasil. 1530 - 1630. São Paulo: Alameda, 2009. 